\title{
Developing neural stem cell-based treatments for neurodegenerative diseases
}

James A Byrne $e^{1,2}$

See related research by Blurton-Jones et al. http://stemcellres.com/content/5/2/46

\begin{abstract}
Owing to the aging of the population, our society now faces an impending wave of age-related neurodegenerative pathologies, the most significant of which is Alzheimer's disease. Currently, no effective therapies for Alzheimer's disease have been developed. However, recent advances in the fields of neural stem cells and human induced pluripotent stem cells now provide us with the first real hope for a cure. The recent discovery by Blurton-Jones and colleagues that neural stem cells can effectively deliver disease-modifying therapeutic proteins throughout the brains of our best rodent models of Alzheimer's disease, combined with recent advances in human nuclear reprogramming, stem cell research, and highly customized genetic engineering, may represent a potentially revolutionary personalized cellular therapeutic approach capable of effectively curing, ameliorating, and/or slowing the progression of Alzheimer's disease.
\end{abstract}

The recent discovery that neural stem cells (NSCs) can effectively deliver disease-modifying therapeutic proteins throughout the murine brain [1] provides hope for millions worldwide who suffer from neurodegenerative disease. In this commentary, I will attempt to place this important research in a broader historical, technological, and scientific context.

Since the beginning of recorded history, researchers have sought therapeutic biologics capable of rejuvenating

\footnotetext{
Correspondence: jbyrne@mednet.ucla.edu
${ }^{1}$ Department of Molecular and Medical Pharmacology, 650 Charles E. Young

Correspondence: jbyrne@mednet.ucla.edu
${ }^{1}$ Department of Molecular and Medical Pharmacology, 650 Charles E. Young Drive South, 23-120 Center for Health Sciences, University of California, Los

Angeles, CA 90095, USA
${ }^{2}$ Eli and Edythe Broad Center of Regenerative Medicine and Stem Cell

Angeles, CA 90095, USA
${ }^{2}$ Eli and Edythe Broad Center of Regenerative Medicine and Stem Cell Research, 615 Charles E. Young Drive South, University of California, Los Angeles, CA 90095, USA
}

(c) 2014 Byrne; licensee BioMed Central Ltd. The licensee has exclusive rights to distribute this article, in any medium, for 12 months following its publication. After this time, the article is available under the terms of the Creative Commons Attribution License (http://creativecommons.org/licenses/by/4.0), which permits unrestricted use, distribution, and reproduction in any medium, provided the original work is properly credited. The Creative Commons Public Domain Dedication waiver (http:// creativecommons.org/publicdomain/zero/1.0/) applies to the data made available in this article, unless otherwise stated. as technological advances have permitted remarkable increases in both human life expectancy and the percentage of the adult population surviving into old age [3]. However, the discovery of technologies to extend our lives has far outpaced our ability to maintain our minds as we age, and our rapidly aging population means we now face an impending wave of the age-related neurodegenerative pathology, Alzheimer's disease (AD). Forecasts indicate that by 2050, in the United States alone, over 13 million people will suffer from AD [4]. Novel cellular therapies built on new technologies are beginning to be developed for a broad range of diseases, and AD offers a potentially promising indication.

NSCs, derived from pluripotent stem cells, are capable of improving cognitive function in preclinical rodent models of $\mathrm{AD}[5,6]$. However, NSCs alone do not remove the amyloid-beta $(A \beta)$ plaques, which (alongside tau-based neurofibrillary tangles) may represent a partial cause of the AD pathology. Neprilysin is a potent proteolytic enzyme that is the rate-limiting enzyme involved in the degradation of $A \beta$ and is found at decreased levels in $\mathrm{AD}$ brains. Although virally mediated delivery of neprilysin can reduce $A \beta$ pathology in murine brains, the potential application of this viral approach for much 
larger human brains is restricted because of its limited radius of infectivity. NSCs offer a potential solution to this clinical bottleneck of narrow viral delivery. NSCs are highly migratory in nature and thus may be suitable for delivering secreted neuro-therapeutics throughout the entire human brain, an activity that NSCs could perform alongside their other putative cognitive functional improvements. These NSCs could be genetically modified to secrete neprilysin or other therapeutic transgenes (or both) for the treatment of AD and other neurodegenerative pathologies, such as Parkinson's disease, stroke, and amyotrophic lateral sclerosis.

Blurton-Jones and colleagues have now demonstrated that NSCs can effectively deliver disease-modifying therapeutic proteins throughout the brain of our best rodent models of AD [1]. They generated murine NSC lines that overexpressed neprilysin, and subsequently transplanted these cells into transgenic models [1]. The NSCs survived and continued to function for at least several months post transplantation, they markedly reduced the $A \beta$ pathology associated with $A D$, and they enhanced synaptic connectivity [1]. This exciting work brings us one step closer to advancing NSC-based biologics into therapies for AD. However, it is important to note that the commonly used human whole fetal graft [7], or NSCs derived from fetal tissue, would not be immunologically matched to the recipient, as it was in the study by Blurton-Jones and colleagues. It is unclear how effective this allogeneic transplantation would be in a somewhat immuno-privileged area, such as the brain. However, recent research demonstrates that significantly higher numbers of autologous (as opposed to allogeneic) neurons have survived in the primate brain following transplantation [8]. A potential solution to this immune rejection problem would be the lifelong administration of immunosuppressive drugs to the patient in order to minimize the immune response in the brain. However, immunosuppressive drugs are expensive, inconvenient, and toxic. Moreover, previous research suggests that they do not appear to significantly improve allogeneic graft survival and may even reduce it [7], making the proposed immunosuppressive drug solution less than ideal.

An alternative approach, which has become increasingly feasible in light of recent discoveries, would be to generate autologous NSCs from human induced pluripotent stem cells (hiPSCs), which themselves have been derived from suitable patient cells, such as skin cells (Figure 1). These cells could be genetically modified in a manner similar

\section{Patient with neurodegenerative disease}

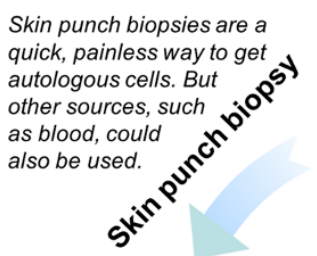

Skin-derived primary cell culture

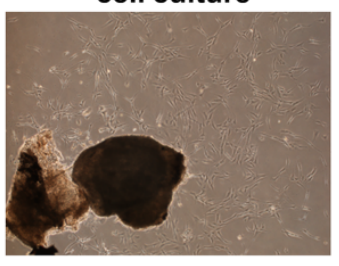

Human induced

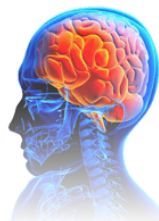
pluripotent stem cells
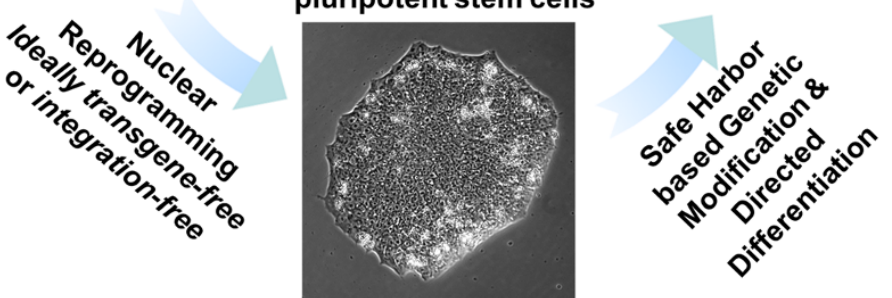

Figure 1 Developing the neural stem cell-based approach for treating Alzheimer's disease. The concept of using human induced pluripotent stem cells (iPSCs) and their neural stem cell (NSC) derivatives, alongside safe-harbor targeted genetic engineering, to develop a personalized cellular therapy for Alzheimer's disease. Clinically relevant human iPSCs (passage 7) were derived from skin punch biopsies, differentiated into NSCs, and (as shown on the right) stained Pax6 (green), Sox1 (red) and DAPI (blue). The figure is based on unpublished data of Kaitlin Ingraham, Patricia Phelps, and James Byrne. See JA Byrne, unpublished data, 2014 and [10]. 
to the NSC modification process implemented by Blurton-Jones and colleagues. However, there are concerns that randomly integrated viral vectors (as used in approaches such as the study by Blurton-Jones and colleagues) may induce insertional mutagenesis in a subset of cells, which then would present an increased neoplasm risk [9]. The optimal method for genetic modification of hiPSC-derived NSCs would therefore probably involve avoiding this randomly integrated viral vector approach.

One solution to this insertional mutagenesis problem would be the use of powerful, flexible, and inexpensive genome-editing technologies, such as the recently discovered CRISPR/Cas9 system, for safe-harbor-based targeting in hiPSCs. It is anticipated that this safe-harbor framework will soon enable scientists and clinicians to generate hiPSCNSCs that are genetically modified to express almost any other therapeutically relevant factor without risking random insertional mutagenesis. Recent reports indicate that implanted iPSC-derived NSCs have demonstrated the ability to survive, migrate, and differentiate and to restore lost neurological function [11]. Such reports and the astonishing pace of stem cell-based regenerative medicine provide hope that new advances will continue to resolve the clinical hurdles faced by hiPSC-based therapeutics for neurodegenerative diseases [9].

In conclusion, modified NSCs may represent a critically needed solution to the inevitably increasing prevalence of $\mathrm{AD}$ in contemporary society.

\section{Abbreviations}

AD: Alzheimer's disease; Aß: Amyloid-beta; hiPSC: Human induced

pluripotent stem cell; NSC: Neural stem cell.

\section{Competing interests}

The author declares that he has no competing interests.

\section{Acknowledgements}

The author would like to thank Patricia Phelps and Kaitlin Ingraham for providing the characterization data for the hiPSC-derived NSCs in Figure 1.

Published: 30 May 2014

\section{References}

1. Blurton-Jones M, Spencer B, Michel S, Castello NA, Agazaryan AA, Davis RP, Müller F, Loring JF, Masliah E, LaFerla FM: Neural stem cells geneticallymodified to express neprilysin reduce pathology in Alzheimer transgenic models. Stem Cell Res Ther 2014, 5:46.

2. Unknown: The Epic of Gilgamesh, 1200 BC. Reprint. Translated by George A. London: Penguin Books; 2003.

3. Oeppen J, Vaupel JW: Demography. Broken limits to life expectancy. Science 2002, 296:1029-1031.

4. Hebert LE, Scherr PA, Bienias JL, Bennett DA, Evans DA: Alzheimer disease in the US population: prevalence estimates using the 2000 census. Arch Neurol 2003, 60:1119-1122.

5. Wang Q, Matsumoto Y, Shindo T, Miyake K, Shindo A, Kawanishi M, Kawai N, Tamiya T, Nagao S: Neural stem cells transplantation in cortex in a mouse model of Alzheimer's disease. J Med Invest 2006, 53:61-69.

6. Moghadam FH, Alaie H, Karbalaie K, Tanhaei S, Nasr Esfahani MH, Baharvand $\mathrm{H}$ : Transplantation of primed or unprimed mouse embryonic stem cell-derived neural precursor cells improves cognitive function in Alzheimerian rats. Differentiation 2009, 78:59-68.
7. Freed CR, Breeze RE, Rosenberg NL, Schneck SA, Kriek E, Qi JX, Lone T, Zhang YB, Snyder JA, Wells TH, Ramig LO, Thompson L, Mazziotta JC, Huang SC, Grafton ST, Brooks D, Sawle G, Schroter G, Ansari AA: Survival of implanted fetal dopamine cells and neurologic improvement 12 to 46 months after transplantation for Parkinson's disease. N Engl J Med 1992, 327:1549-1555.

8. Morizane A, Doi D, Kikuchi T, Okita K, Hotta A, Kabasawa Y, Hayashi Y, Onoe $H$, Shiina T, Yamanaka S, Takahashisee J: Direct comparison of autologous and allogeneic transplantation of iPSC-derived neural cells in the brain of a nonhuman primate. Stem Cell Reports 2013, 1:283-292.

9. Byrne JA: Resolving clinical hurdles for autologous pluripotent stem cell-based therapies. OA Stem Cells 2013, 1:3.

10. Awe JP, Lee PC, Ramathal C, Vega-Crespo A, Durruthy-Durruthy J, Cooper A, Karumbayaram S, Lowry WE, Clark AT, Zack JA, Sebastiano V, Kohn DB, Pyle AD, Martin MG, Lipshutz GS, Phelps PE, Pera RA, Byrne JA: Generation and characterization of transgene-free human induced pluripotent stem cells and conversion to putative clinicalgrade status. Stem Cell Res Ther 2013, 4:87.

11. Yuan T, Liao W, Feng NH, Lou YL, Niu X, Zhang AJ, Wang Y, Deng ZF: Human induced pluripotent stem cell-derived neural stem cells survive, migrate, differentiate, and improve neurological function in a rat model of middle cerebral artery occlusion. Stem Cell Res Ther 2013, 4:73.

\section{$10.1186 /$ scrt461}

Cite this article as: Byrne: Developing neural stem cell-based treatments for neurodegenerative diseases. Stem Cell Research \& Therapy 2014, 5:72 